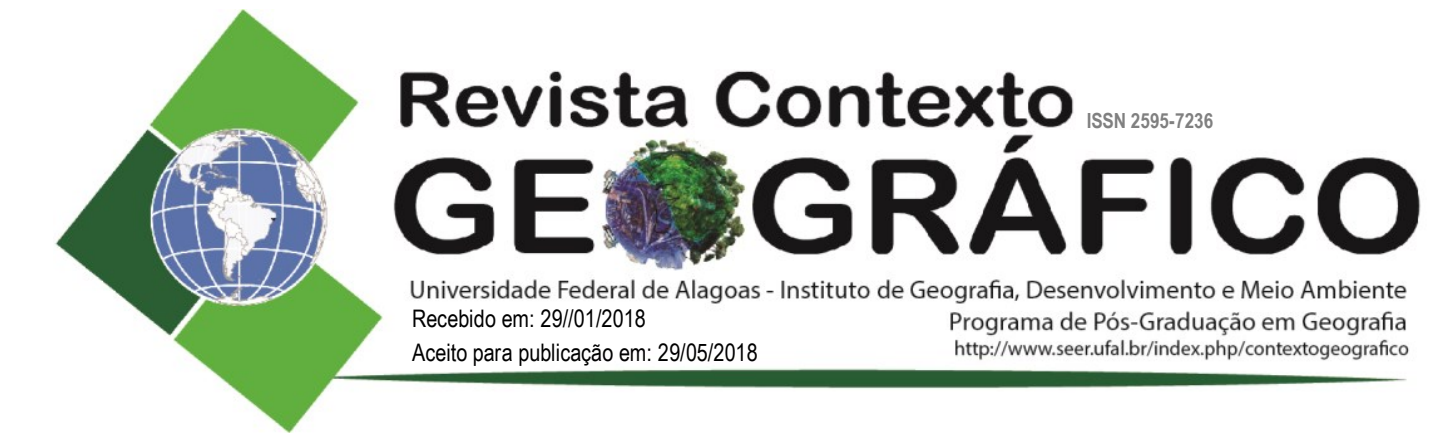

\title{
O PODER DA FERROVIA E DO ENGENHO (DES)CONSTRUINDO O PAPEL REGIONAL DE PILAR: DA "PROSPERIDADE" A LETARGIA DO TERRITÓRIO
}

\author{
Thiago Calheiros Dantas \\ Mestrando em Geografia, Universidade Federal de Alagoas, Instituto de Geografia, \\ Desenvolvimento e Meio Ambiente, Maceió, AL, Brasil \\ thiagocalheirosdantas@gmail.com
}

Antonio Alfredo Teles de Carvalho

Universidade Federal de Alagoas, Instituto de Geografia, Desenvolvimento e Meio

Ambiente, PPGG, IGDEMA, Maceió, AL, Brasil

acarvalho@igdema.ufal.br

\begin{abstract}
RESUMO - O estudo propõe analisar as mudanças do modal lacustre para ferroviário na cidade de Pilar - Alagoas e os seus efeitos na constituição de um território marcado pela letargia. A mudança do meio técnico com o advento das ferrovias no território alagoano e a extinção da Companhia de Navegação a Vapor das Lagoas Norte e Manguaba (1868-1902), alterou a intensidade do fluxo de pessoas e mercadorias na região lagunar que então constituía um importante entreposto comercial, ou espaço de transbordo. Nesse interstício os engenhos escoavam a sua produção via laguna, evidenciando o poder dos coronéis em seus partidos de cana e Pilar vivia o seu apogeu. Porém, a construção do trecho ferroviário Maceió-Viçosa representou o fim dessa realidade e das possibilidades de Pilar continuar economicamente se desenvolvendo, visto que a decadência do centro de transbordo da região lagunar privilegiou o escoamento do açúcar através das vias férreas e fortaleceu a influência econômica de Maceió, no contexto alagoano. Posteriormente Pilar não conseguiu reunir condições para retomar o "progresso" de antes, passando então, a depender decisivamente da capital alagoana.
\end{abstract}

Palavras-chave: Território, Entreposto, Ferrovia, Letargia.

\section{THE POWER OF THE RAILROAD AND THE ENGINE (DES) BUILDING THE REGIONAL ROLE OF PILAR: FROM "PROSPERITY", THE LITARIAN OF THE TERRITORY}

\begin{abstract}
The study proposes to analyse to the changes of modal lake for railway in Pilar Alagoas and its effects in the constitution of territory marked by lethargy. The change of the technical means, according to railways arrival in Alagoas and the end of the Steam Navigation of the Lagons Norte and Manguaba Company (1868-1902), modified the intensity of people and merchandise flow at lagoon areas, which, at the moment, compose an important comercial warehouse or transhipment space. In this interstice, the mills drained their productions by the lagoon, showing the power of the colonels in their entourage cane and Pilar lived his apogee. But, the build of the railway stretch Maceió-Viçosa meant the end of this reality and of possibilities for Pilar to continue to develope his economy, as the decadence of transhipment center of the lagoon region privileged the flow of the sugar through the railways and stengthened the economic influence of Maceió at the context of Alagoas. After, Pilar wasn't able to find a way to recover the "progress" he used to have, coming to depende decisively on the capital of Alagoas.
\end{abstract}

Keywords: Territory, Warehouse, Railway, Lethargy. 


\section{CONSIDERAÇÕES INICIAIS}

O artigo propõe investigar as mudanças do modal lacustre para ferroviário em Pilar-Alagoas e os seus efeitos na constituição de um território letárgico entre 1868 e 1894, quando se deu um grande desenvolvimento econômico, seguido de seu declínio.

O desenvolvimento econômico de Pilar já se mostrava considerável quando ainda era um povoado. Com efeito, em menos de seis anos saiu da condição de Freguesia para cidade. Acreditase que tal desenvolvimento seja decorrente do êxito dos engenhos, que 1859 já totalizavam vinte e uma unidades. Anos depois, a cidade continuou conhecendo grande desenvolvimento econômico, vindo a se tornar um centro de transbordo ou entreposto comercial na dinâmica regional alagoana. Pois, recebia do leste e oeste do estado, açúcar e outras mercadorias que eram transportadas nos lombos de escravos e animais. Essas mercadorias, ao chegarem no entreposto aguardavam apenas os vapores para o Porto de Jaraguá.

O fim da Companhia de Navegação a Vapor das Lagoas Norte e Manguaba (1868-1902) e a estruturação do trecho férreo Maceió-Viçosa (Atalaia, Rio Largo e Maceió), promoveram o rearranjo do território pilarense, quebrando a lógica do entreposto comercial. É importante observar que o fim dessa lógica está associado à priorização do escoamento da produção açucareira na época, considerando que o trecho mencionado fazia parte de um grande arranjo que integrava às proximidades das áreas de produção canavieira a capital e ao Agreste (Maceió, Rio Largo, Atalaia, Viçosa, Quebrangulo, Palmeira dos Índios, Igaci, Arapiraca e Porto Real do Colégio). Destaque-se, ademais que na região do sertão alagoano também existiam linhas férreas, nas cercanias do Rio São Francisco (Piranhas e Delmiro Gouveia), seguindo à cidade de Petrolândia em Pernambuco.

\section{ALGUMAS CONSIDERAÇÕES SOBRE A DINÂMICA DO TERRITÓRIO PILARENSE ENTRE 1868-1902}

Entre 1868 e 1902, Pilar é dominada pelo latifúndio atrelado a produção de açúcar, fluxos de mercadorias procedentes do interior alagoano, transportadas no centro de transbordo pelos vapores, e as industriais têxteis. Observe-se que nesse período o território é obediente as ações advindas dos donos da "Casa grande", senhores de engenho, agente racionalizador do tempo, da produção, da exploração daqueles que trabalham na terra.

Contudo, percebe-se que no território existem temporalidades hegemônicas e hegemonizadas. No dizer de Santos (1997, p.13) "as primeiras são o vetor da ação dos agentes hegemônicos da economia, da política e da cultura, da sociedade enfim. Os outros agentes sociais, hegemonizados pêlos primeiros, devem contentar-se de tempos mais lentos". Logo, o território vai sendo moldado, sobretudo em prol daqueles que detém os meios necessários para circulação do capital e nele aparecem características significativas que são as permanências do tempo que ajudam a reconstituir sua história. Esses dados de tempo expressam também uma base técnica que porventura serviu ou serve para desenvolver os lugares. Geralmente essas permanências são continuidades dos fluxos econômicos hegemônicos, ligados a produção de riquezas, e se realizam em detrimento dos tempos lentos vividos pelos mais pobres.

A ação hegemônica dos engenhos de açúcar em Pilar se configurava pela casa grande, o engenho fabricando açúcar, a capela, o pelourinho e a senzala, mais a mão-de-obra escrava e alguns trabalhadores livres responsáveis pela produção escoada à Praça do Desembarque, fundada em 1868 para atender o transporte de pessoas e mercadorias via laguna.

A configuração do território pilarense em grandes latifúndios propiciou a acumulação de capital para os "coronéis da cana", explorando a mão-de-obra que dispunham, os recursos naturais e os 
diferentes objetos técnicos disponíveis para alavancar essa produção monocultora. Com relação ao uso e a combinação dos diferentes objetos técnicos para impulsionar o lucro, mostra Santos (1997, p. 30) que "a combinação, num lugar, de técnicas de idades diferentes, significa, em cada momento histórico, possibilidade local de acumulação ou dessa acumulação do capital em virtude da rentabilidade diferencial devida aos modos de produção concretos". Ou seja, os sistemas técnicos são distribuídos nos lugares de forma intencional, sejam os mais modernos ou antigos podem ser incorporados ou combinados ao arranjo do território para fazer girar as engrenagens do capital e permitir o lucro daqueles que detém os meios de produção.

Nesse sentido, lembra Silveira $(2011$, p. 2) que "cada período produz suas forças de concentração e dispersão, resultado da utilização combinada de condições técnicas e políticas, que não podem ser confundidas com as de momentos pretéritos e que redefinem os limites". Assim, cada período histórico marca o território com uma base técnica e poder político, impostos pelas intenções daqueles que detêm o poder.

No período em pauta, Pilar era marcada por uma configuração territorial que tinha nos mandos dos senhores de engenho o seu principal vetor, com influências política, econômico e social, dentro e fora do território alagoano. A Figura 1 retrata um momento da paisagem cultural da freguesia pilarense, deixando clara a forma como o território foi constituído para dar lucro, através dos engenhos de açúcar. Destacando-se ao fundo a casa grande e nas suas proximidades, a vila operária com alguns casarões que estocavam o açúcar e também serviam como abrigo daqueles que trafegavam pela freguesia.

Figura 1. Fotografia de um dos engenhos de cana de açúcar em Pilar de 1869

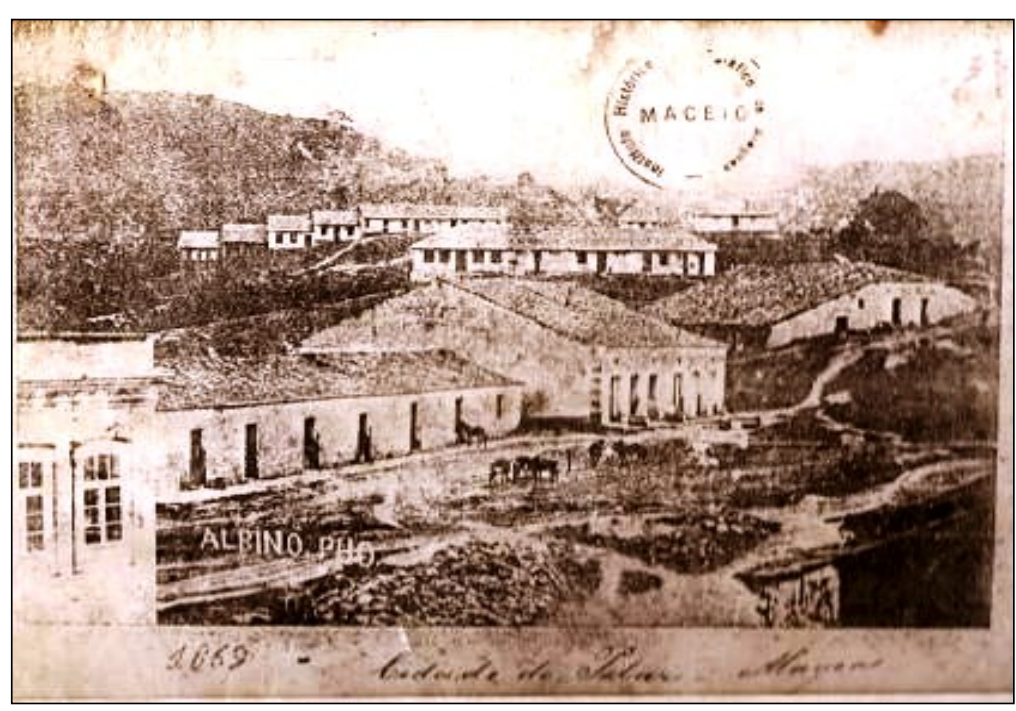

Fonte: http://pilar-al.webnode.com.br/pilar-antigo

Conforme Carvalho (2009, p.10) "a estrutura de propriedade da terra, com o conseqüente sistema de poder, criado nos três primeiros séculos de colonização, marcou para sempre o modelo econômico e social de Alagoas". Assim, a propriedade da terra e seus usos obedeciam aos comandos dos donos de engenho que constituíam relações sociais niveladas pelo poder econômico das famílias. O poder do engenho normatiza as relações existentes nas terras do fundo de vale, mediante os mandos dos "doutores coronéis.

O crescimento da economia açucareira em Pilar, na segunda metade do século XIX, se revela nos catorze engenhos existentes. Número expressivo e que lhe confere ainda mais destaque. $\mathrm{O}$ 
progresso do Povoado foi tão significativo que segundo Moraes $(2005$, p.16) "em 08 de Maio de 1854, através da Lei Provincial No 250, foi criada a Freguesia de Nossa Senhora do Pilar e três anos depois, em $1^{\circ}$ de Maio de 1857, através da Lei Provincial $N^{\circ} 321$, PILAR foi elevada a categoria de VILA".

Em 1859 o número de engenhos existentes passou de 14 para 21, segundo mostra a análise do "Mapa Demonstrativo do Açúcar da Província das Alagoas", exposto na tabela 1. A produção nos engenhos era quantificada em pães de açúcar (que consistia no açúcar granulado para exportação) e cristais obtidos durante a purga do açúcar, daí estocados e embalados para o comércio. A maior produção de pães de açúcar estava concentrada em três engenhos: Lameirão, Grajaú de Baixo e Flor do Paraíba que produziam individualmente em média de 2.200 a 2.500 pães de açúcar em 1859.

Tabela 1. Dados dos engenhos de açúcar encontrados na vila do Pilar no ano de 1859

\begin{tabular}{|c|c|c|c|}
\hline ENGENHOS & DISTRITO & PROPRIETÁRIO & PRODUÇÃO \\
\hline 1.Lameirão & Vila do Pilar & Nicolau Alves Rodrigues & 2.200 a 2.500 \\
\hline 2.Grujaú de Baixo & Vila do Pilar & Joaquim José de Melo & 2.200 a 2.500 \\
\hline 3.Flor do Paraíba & Vila do Pilar & José Antônio de Mendonça & 2.000 a 2.200 \\
\hline 4.Engenho Nôvo & Vila do Pilar & Ernesto Lopes Rodrigues & 1.800 a 2.000 \\
\hline 5.Brejo Novo & Vila do Pilar & Viúva de Antônio Cavalcante & 1.800 a 2.000 \\
\hline 6.Mumbaça & Vila do Pilar & Joaquim Lopes Rodrigues & 1.800 a 2.000 \\
\hline 7.Poção & Vila do Pilar & José Joaquim Maia & 1.700 a 1.800 \\
\hline 8.Grujaú de Cima & Vila do Pilar & D. Maria Madalena da Costa & 1.400 a 1.500 \\
\hline 9.Boacica & Vila do Pilar & Frutuoso Joaquim Maia & $1.400 \quad 1.500$ \\
\hline 10.Camurupim & Vila do Pilar & Nicolau Alves Rodrigues & 1.200 \\
\hline 11.Terra Nova & Vila do Pilar & Antônio Carlos da Silva & 1.200 \\
\hline 12.Pilarzinho & Vila do Pilar & Francisco Estêves & 1.000 \\
\hline 13.Salgado & Vila do Pilar & Cap. Antônio José Correia & 1.000 \\
\hline 14.Mangabeira & Vila do Pilar & Henrique Hernesto Bittencourt & 500 \\
\hline 15.Chã & Vila do Pilar & Inácio José de Godóes & 800 \\
\hline 16.Rachado & Vila do Pilar & Domingos José da Costa Agra & 1.000 \\
\hline 17.Volta & Vila do Pilar & Silvestre Domingues da Silva & 800 \\
\hline 18.Quebra Carro & Vila do Pilar & João do Reno Acioli & 600 \\
\hline 19.Subaúma & Vila do Pilar & Inácio Acioli Vasconcelos & 800 \\
\hline 20.Cajueiro & Vila do Pilar & Antônio Corrêa da Mota & 600 \\
\hline 21.Utinga & Vila do Pilar & Manoel da Cunha R. Lima & 1.000 \\
\hline
\end{tabular}

Fonte: SANT’ANA, M. M. Contribuição à história do açúcar em Alagoas. Maceió: Imprensa Oficial, 2011. Organização: DANTAS, T. C., 2017

Enquanto freguesia, Pilar possuía particularidades muito interessantes de serem analisadas dentro do recorte temporal estabelecido. Especialmente pelo significativo desenvolvimento econômico naquele momento e ser considerada a primeira da província já em 1870. A dinâmica territorial possibilita à Vila uma configuração socioeconômica específica com suas casas de alvenaria, palha, fogos, sítios, correios e até cadeiras de primeiras letras, características constatadas no fragmento de texto adiante. 
No extremo oeste da lagoa Manguaba, a pouco menos de 3 léguas da cidade das Alagoas e a 2 de Atalaia, regada por 4 riachos, - o do BONGA, que passa na rua denominada Pernambu $\neg$ co Novo, o do AÇUDE, que passa por detrás da rua Nova, o do URUBU, que passa atrás da rua Comércio, e o BIQUINHA que desce a ladeira e despeja no Urubu". E continua com a narração, "[...] é a primeira da província pelo seu importante comércio, edificação e povoa-ção; tem 837 fogos, - 10 sobrados, 389 casas de telha e 448 de palha - exclusive a chã da ladeira, chã que tem 165 fogos, -8 casas de telha e 157 de palha -, e a povoação de toda a vila monta a 4.000 almas; tem ela mais três tra $\neg$ piches, 3 igrejas, - matriz, o Rosário e a de S. Benedito, e na chã um nicho de Nossa Senhora da Graça; tem mais ainda uma mesa de rendas gerais, (criada a 16 de julho de 1853) outra de rendas provinciais (criada pelo artigo $1^{\circ}$ da Resolução $n^{\circ} 566$, de 24 de maio de 1870) uma agência do correio e quatro cadeiras de primei $\neg$ ras letras, duas para cada sexo (ESPÍNDOLA apud SANT'ANA 2002, p. 32).

Tal fragmento, leva a perceber a forte influência da religião ao se contar a quantidade de pessoas no local pelo registro do batismo, usando a nomeclatura "alma" ao invés de habitantes, apontandose 4.000; e as igreja Matriz, o Rosário e Santo Benedito, localizadas na planície fluvio-lagunar; e a capela de Nossa Senhora das Graças na Chã em Pilar, situada no tabuleiro costeiro.

A leitura desse fragmento também traz consigo valiosas informações relacionadas ao processo de ocupação do território e sua população, concentrada nas proximidades da Manguaba, planície fluvio-lagunar. Por sua vez, a área que atualmente corresponde a "Chã do Pilar", expressão usada pelos locais, possuía na época alguns fogos, casas de palha e de alvenaria, mantendo aproximadamente a distância da capital de três léguas, sabendo que uma légua pode valer entre 2 a 7 quilômetros.

\section{DO ESPAÇO DE TRANSBORDO À CONSTITUIÇÃO DE UM TERRITÓRIO LETÁRGICO}

"Com o progresso, em 16 de março de 1872, através da Lei $\mathrm{N}^{\circ}$ 624, PILAR garantiu a sua Autonomia Administrativa, se desligando da Comarca de Atalaia e a Lei № 626 da mesma data, lhe outorga o foro de cidade" (MORAES, 2005, p. 16). Ou seja, a antiga freguesia recebe o foro de cidade, desligando-se de Atalaia e garante sua autonomia político-administrativa, respaldada pelo progresso trazido pelo açúcar.

O núcleo embrionário de Pilar está às margens da laguna Manguaba, atualmente conhecido por "Bairro do Torrão", à época, Vila de Pescadores. Inicialmente (século XVI) o território era de propriedade dos índios Cariris. Porém, índios e pescadores utilizaram o território por sua planície de fácil penetração e solo fértil, comodidade do clima tropical úmido, suas matas com os frutos da manguaba - abundantes na época, peixes e crustáceos.

A prosperidade do açúcar às margens da Manguaba dava-se de forma satisfatória, seja pelas características ambientais propícias que levavam o produto a ser competitivo, seja pelo limite técnico da época, destacando o relevo de planície, propício ao plantio, mais a forte presença de corpos d'água - nascentes e rios para uso do engenho e descarte da tibornea, que ainda não era utilizada para adubação do solo. Ademais, acrescente-se que a técnica agrícola de então ainda não permitia o plantio nos tabuleiros, limitando-se as várzeas e planícies.

O desenvolvimento técnico implica também na constituição do território, relacionando-se ao seu desenvolvimento e limites do espaço de trabalho. Conforme Santos (2012, p. 55) "o espaço do trabalho contém técnicas que nele permanecem como autorizações para fazer isto ou aquilo, desta 
ou daquela forma, neste ou naquele ritmo, segundo esta ou outra sucessão. Tudo isso é tempo", ou seja, o território é constituído tanto por técnicas mais simples e pretéritas, quanto pelas técnicas mais sofisticadas, é nele que as diferentes temporalidades se encontram formando uma realidade em plena mudança em vista das decisões de cunho político.

Com efeito, a Companhia de Navegação a Vapor das Lagoas Norte e Manguaba, que de acordo com Sant'ana (2002) inicia suas atividades para o público, no dia 21 de setembro de 1868, naquele momento representa o novo, avanço técnico e revela mudanças. Assim, o transporte via laguna possibilitaria o escoamento dos produtos que chegavam das cidades adjacentes como: Atalaia, Capela e Viçosa. A maior parte das mercadorias que chegavam à região lagunar ia para Praça do Desembarque, destacada na Figura 2.

Figura 2. Vista parcial da Cidade do Pilar em 1894, sendo vista as pontes de embarque e desembarque nas margens da laguna Manguaba

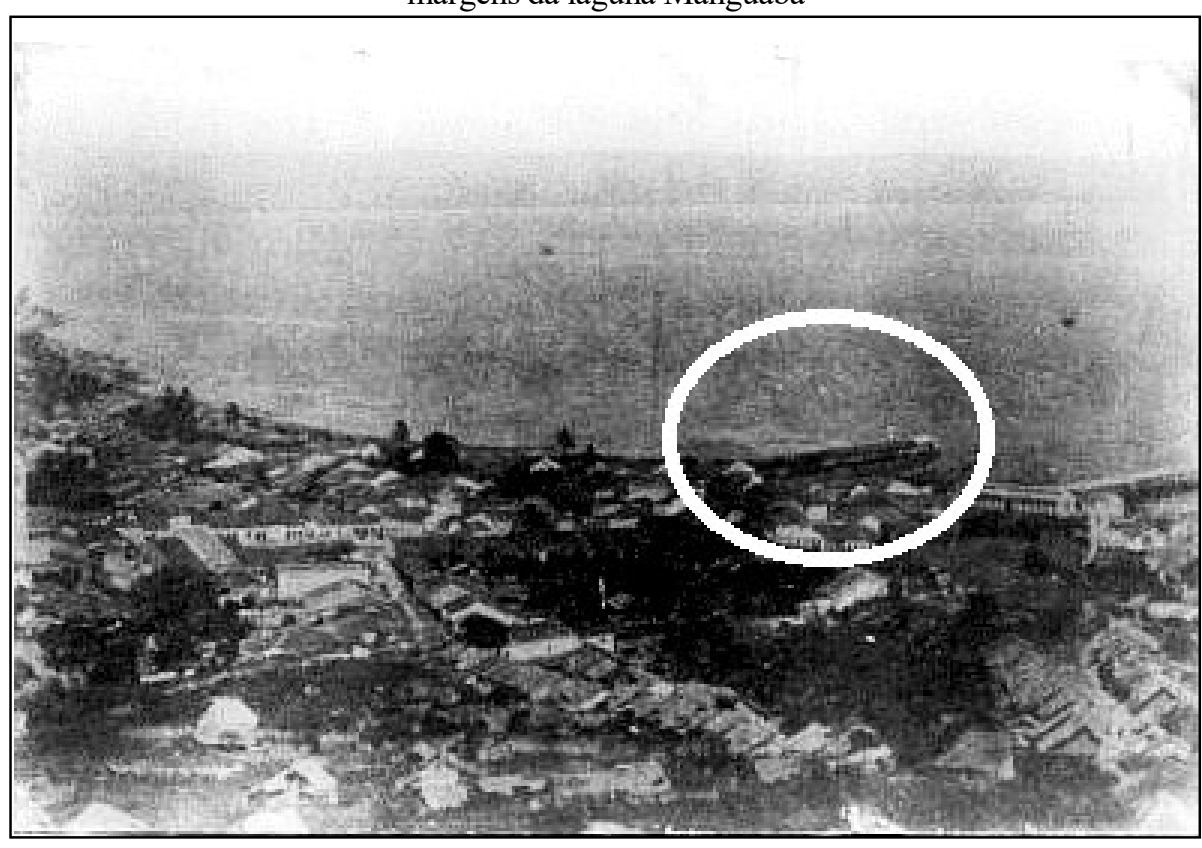

Fonte: http://pilar-al.webnode.com.br/pilar-antigo/

O trafego de mercadorias e pessoas era realizado por quatro vapores: Alagoano, Itaparica, Leopoldina e Henriqueta, objetos técnicos essenciais nesse processo e, por conseguinte para o desenvolvimento econômico de Pilar e adjacências. Com lucidez, mostra Santos (2012, p. 232) que "através de ações normadas e de objetos técnicos, a regulação da economia e a regulação do território vão [...] impor-se com ainda mais força...". Logo, o uso do território perpassa uma base técnica intencionalmente construída para impor força produtiva, regulando a economia e movimentando os ganhos.

Por volta 1875, o desenvolvimento econômico da Companhia de Navegação se mostrava tão exitoso que já aguardava a chegada de mais um vapor encomendado na Inglaterra. $\mathrm{O}$ desenvolvimento econômico da região lacustre chama a atenção do Imperador Dom Pedro II, que em 1860 visitou Pilar no navio Pirajá, junto com a sua comitiva. A chegada do imperador em Pilar é aqui destacada por impulsionar o desenvolvimento de algumas obras públicas, ligadas ao saneamento e transporte em Alagoas. Particularmente em Pilar é estimuladas a obra da construção da Ladeira de Pedras que corta as atuais ruas Marechal Roberto Pereira, João das Virgens Lima e Jacuípe, conhecida pelos populares como Rua da Areia. A conclusão da obra da Ladeira de Pedras 
até os dias atuais facilita o trafego de pessoas e mercadorias, integrando a planície fluvio-lagunar a extremidade do tabuleiro costeiro, na Chã.

O desenvolvimento econômico constitui uma marca de Pilar a partir da segunda metade do século XIX, pois além dos empreendimentos lacustres e canavieiros, também conhece a instalação de algumas empresas ligadas ao ramo têxtil: a Fábrica Pilarense, a Companhia Pilarense de Fiação e Tecidos, implantada no dia 13 de março de 1892 e inaugurada em outubro de 1893; e a Fábrica de Rendas e Bordados do Pilar, inaugurada em 10 de dezembro de 1909 (BARROS, 2005, p. 70). Todas estas empresas empregaram majoritariamente mão-de-obra local, da tecelagem a manutenção do maquinário e serviços de limpeza. O espaço onde funcionavam essas empresas corresponde às imediações da atual Avenida Arthur Ramos.

Observa-se, pois, que o apogeu da economia pilarense no período em questão está intrinsecamente relacionado ao mercado da cana e ao sistema de engenharias de transportes via laguna. Porém, não se pode olvidar as suas especificidades naturais, basilares ao desenvolvimento das indústrias, açucareira, têxtil e o próprio modal lacustre.

Contudo, todo esse desenvolvimento econômico alcançado entraria em declínio com o advento de novos objetos técnicos materializados nas ferrovias que no seu trecho Viçosa-Maceió não contemplou o entreposto com suas estações e trilhos (SÁ, 1976).

Consequentemente, a transferência do sistema de transporte via laguna para ferroviário, incide na decadência econômica de Pilar. A construção da ferrovia ligando Maceió a Viçosa desmerece o centro de transbordo e aniquila seus fluxos, transporte de mercadorias e pessoas para a capital através dos vapores (SILVA, 2006).

Ao analisar o traçado das ferrovias e a localização dos engenhos de açúcar observa Diégues Junior (2006, p.128-129) que "são inúmeros os engenhos que tem suas terras cortadas pela estrada de ferro. A partir do Rocha e o Cajueiro, os dois primeiros encontrados pelo traçado [...] tanto na margem direita como da esquerda da Mundaú". Percebendo-se dessa forma, que a intencionalidade da empresa ferroviária no território alagoano não consistia tão somente em proporcionar melhores condições de fluxo a sua população, mas atender os interesses dos grandes proprietários de terras, latifundiários, senhores de engenho. Assim, ao se instalar um conjunto de objetos técnicos, surgem também normatizações para atingir os objetivos e um conjunto de agentes que pensam no território como fator de produção, aniquilando, redefinindo e criando centralidades.

Ademais, os interesses políticos foram determinantes nesse processo que resultou em profundas mudanças na dinâmica econômica em Pilar, implicando na reorganização dos seus fluxos e enterrando a possibilidade de a cidade continuar com o seu importante papel de entreposto comercial, conduzindo-a a um estado de letargia. Alguns dos engenhos mesmo distantes incialmente da linha ferrea, mas que seus produtos convergiam para as estações e locomotivas estavam nas cidades de Capela, Viçosa e Pilar ou em Atalaia, sendo eles

Coité Velho, Conceição, Mundaú, Varge Grande, Sítio do Meio, Gregório, Satuba, Sapucaia, Campinas, Jardim, Cachoeira, Satuba Segundo, Coitezinho, Utinga, Pinto, Pedra Grande, Cafundó, Garça Torta, Coité Novo, Oficina, Lagoa de Una, Rio Largo, Pau Amarelo, Riachão, Bom Jardim, Água Clara, Urucu, Gitirana, Itamaracá, Pindoba, Cabaços, Remédio, Boa Vista, Bom Regalo, Salamanquinha, Antas, Caroatá, Camboim, Goiana, Duas Ruas, Dois Galhos e Cachoeira Grande (DIÉGUES JUNIOR, 2006, p. 129). 
A respeito do poder político dos coronéis, assevera Carvalho (2015, p. 153) que "o coronel traça os rumos das relações sociais e políticas da localidade ao concentrar em suas mãos o domínio econômico, o poder de justiça, ao nomear juiz e delegado, e até mesmo religioso [...] $\mathrm{O}$ 'código do coronel' é o poder do mais forte". Logo, a constituição dos privilégios para a classe dominante não somente em Pilar, mas em Alagoas, leva a formação de um território normado pelos coronéis, planejado para atender os seus interesses, a sua perpetuação.

O primeiro recorte do território alagoano contemplado pela via férrea foi o trecho Petrolândia (PE) - Delmiro - Piranhas (AL), entre 1881 e 1883. Posteriormente foram implantados os trechos Maceió - Rio Largo - União, entre 1884 e 1894; Atalaia -Viçosa 1891 a 1911; o trecho do Agreste aparece entre 1912 a 1950, cobrindo as cidades de Quebrangulo, Palmeira dos Índios, Igaci, Arapiraca e Porto Real do Colégio (CORRÊA, 1992).

As vias férreas entre Maceió, Rio Largo e União foram construídas entre 1884 e 1894, transportando as mercadorias das regiões banhadas pelos rios Paraíba e Mundaú, na atual Messoregião do Leste alagoano, alcançando o extremo norte do Estado, em Santana do Mundaú e São José da Laje. É importante destacar que grande parte dos trechos aludidos atualmente encontram-se desativados. Nessa perspectiva, destaca Corrêa (1992, p.102) que "a vida urbana alagoana foi profundamente alterada com o advento da ferrovia, causando verdadeira revolução". Houve mudanças do fluxo econômico de algumas cidades, sobretudo, aquelas que possuíam o transporte de mercadorias através de rios, canais e lagunas.

Economicamente as cidades alagoanas sentiram o impacto da chegada da ferrovia, seja de forma positiva ou negativa. A título de exemplo, as denominadas cidades "ponta de trilho" ascenderam por algum tempo o fluxo econômico. Este é particularmente o caso de Delmiro Golveia, Piranhas, Porto Real do Colégio, Arapiraca, Palmeira dos índios, Viçosa, Atalaia, Rio Largo, Maceió e União dos Palmares (CORRÊA, 1992). O novo modal de transporte ajudou também na redefinição dos papeis das cidades alagoanas face a dinamização dos novos usos do território.

Nesse sentido, convém ressaltar que "reformulam-se os papéis das antigas cidades, mas também das mais recentes [...] geralmente com certo abandono de funções ligadas ao abastecimento da população e com a implantação de funções para o abastecimento de atividades modernas" (SILVEIRA, 2010, p. 04). Ao referir-se à racionalidade do capital no território a autora conduz à compreensão que muitos lugares são alvo das intencionalidades dos agentes hegemônicos, "da modernidade", o que pode levar a (re)organização do território e ao aparecimento da desigualdade, a depender do seu uso.

A construção da via férrea deixou fortes marcas nas paisagens urbanas e lagunar de Pilar. A efervescência comercial da Praça do Desembarque desapareceu, a feira da parte baixa foi dramaticamente reduzida. Considerando essa mudança mostra Corrêa (1992, p. 102) que "estas modificações dizem respeito, inicialmente, à decadência de um próspero centro, Pilar, e a acentuação da importância de um outro, Maceió, que já desfrutava das vantagens que os transportes marítimos lhe haviam conferido". Além de Pilar, Coqueiro Seco e Santa Luzia do Norte também perderam a funcionalidade como "centro de transbordo". Assim, fica evidente que a decadência de alguns lugares pode levar a prosperidade, a decadência ou a manutenção do poderio econômico de outro. O estado de letargia do território pilarense se dá em prol da ascensão política e econômica da capital, Maceió, e dos "doutores coronéis". Afinal, o seu papel na dinâmica regional alagoana de então não constituía "cabeça de trilho", nem "centro expansão". Ou mesmo, "centro da economia regional", mas um centro de transbordo. Sobre o papel regional de Pilar em comparação a Penedo pode-se dizer que

Ao contrário de outros centros, como Penedo, ela não pode manter, pela tradição, à força dos mecanismos de comércio, um certo papel na vida de relações da região. Isto se explica por Pilar nunca ter sido cabeça de rede 
urbana, e sim um centro de transbordo, próximo de Maceió e na sua dependência direta (CORRÊA, 1992, p. 103).

Pilar, era na verdade, um centro de transbordo ou entreposto comercial, território de passagem de pessoas e mercadorias face ao meio de transporte lacustre. Portanto, diferente de Penedo que mesmo perdendo significativamente a intensidade do fluxo comercial via São Francisco e trilhos, continua como "cabeça de rede urbana", (CORRÊA, 1992).

Compreende-se, dessa forma, que o papel de "cabeça de rede urbana" corresponde a uma cidade que orienta a dinâmica econômica regional, influenciando e atraindo pessoas das cidades adjacentes em busca de serviços, possuindo também a capacidade de manter sua dinâmica econômica, sem a dependência exclusivista de uma cidade e setor que norma o cotidiano daqueles que vivem em seus lugares (CORRÊA, 1992).

A alteração do papel regional de Pilar é redefinido pelo fluxo da sua economia. As casas comerciais já não mais importavam da Europa e os casarões que permaneceram na paisagem são resultado de um período áureo que a cidade viveu. Com efeito,

em 1922, quando a decadência do Pilar já era um fato comprovado, não mais existiam as grandes casas comerciais que importavam diretamente da Europa, nesse ano, registrava num quase lamento Alberto Marroquim, em sua obra Terra das Alagoas: - 'A cidade de Pilar, sede do município do mesmo nome, que muito tempo chegou a dominar, pelo incremento do seu comércio, vive hoje da recordação desses tempos áureos, guardando no aspecto de muitos edifícios os vestígios da passada grandeza (SANT'ANA, 2002, p.42-43).

O apogeu econômico ficou na história e na memória das pessoas. Incrustado nas suas paisagens, por exemplo, nos casarões de estilo colonial, na igreja de Nossa Senhora do Pilar, no Cine Pilarense, na antiga delegacia situada na planície flúvio-lagunar; e ainda no que restou dos galpões que estocavam os produtos que chegavam à cidade.

Em relação a alteração da base material e o território ressalta Silveira (2011, p. 01) que "as bases materiais e imateriais historicamente estabelecidas são apenas condições. Seu verdadeiro significado advém das ações sobre elas realizadas. O território usado é, por isso, movimento permanente". As bases técnicas são dessa forma, fatores importantes a serem analisados nas paisagens. Entretanto, é necessário ir além das formas e buscar compreender as ações que possibilitam os usos do território, agentes, intencionalidades, movimentos, permanências e contextos. Partindo do pressuposto, as permanências não devem ser encaradas como sinônimo de eternidade, uma vez que o espaço está em constante transformação.

A perda do papel regional de Pilar leva a entender que na segunda metade do século XIX e inicio do século XX o território foi edificado para atender as normatizações de um seleto grupo de agentes, apenas preocupados com a exploração dos seus recursos naturais e da mão de obra local, tendo como foco o lucro incondicional, especialmente da economia canavieira.

\section{BREVES CONSIDERAÇÕES FINAIS}

No interstício correspondente ao recorte temporal aqui analisado, o promissor território pilarense é normado pelos coronéis no contexto de um meio técnico consonante com as exigências dos senhores de engenho e os seus latifúndios, ancorados na exploração da terra, dos trabalhadores e o escoamento da sua produção através das lagunas e canais. Entretanto, o declínio e a consequente extinção da 
companhia responsável pelo transporte lagunar, decorrente do advento das vias férreas em Alagoas especialmente o trecho Viçosa-Maceió, mudaria essa realidade e, por conseguinte, retiraria de Pilar o seu papel de espaço de transbordo, lhe condenando a um estado de letargia.

Com efeito, a construção do trecho ferroviário Maceió - Viçosa findou as possibilidades de Pilar continuar o ritmo de desenvolvimento econômico que vinha alcançando. Observa-se que a extinção do centro de transbordo da região lagunar estava relacionada a uma outra intencionalidade dos coronéis de então. Qual seja, favorecer o escoamento do açúcar através das vias férreas que cortavam os canaviais, e a possibilidade de estimular e consolidar a influência econômica de Maceió em Alagoas.

Posteriormente, Pilar, não conseguiu retomar o seu desenvolvimento econômico. Tornou-se um território marcado pela letargia e cada vez mais dependente dos serviços oferecidos por Maceió e atualmente integra a sua região metropolitana. Porém, continua dominada pelos latifúndios sucroalcooleiros, mesmo perdendo parte de sua área plantada de cana nos últimos anos.

\section{REFERÊNCIAS}

BARROS, Francisco Reinaldo Amorim de. ABC das alagoas: dicionário biobibliográfico, histórico e geográfico de alagoas. Brasília: Senado Federal, conselho editorial, 2005. Disponível em: <www.senado.gov.br/publicacoes/conselho/asp/pdf.> Acesso em 22 de março de 2012.

CARVALHO, Cícero Péricles de. Análise da reestruturação produtiva da agroindústria sucroalcooleira alagoana. $3^{\circ}$ ed. Maceió: Edufal, 2009.

CARVALHO, Cícero Péricles de. Formação histórica de Alagoas. $3^{\circ}$ ed. Maceió: Edufal, 2015.

CORRÊA, Roberto Lobato. A vida urbana em Alagoas: a importância dos meios de transporte na sua evolução. Disponível em: <https://www.agb.org.br/publicacoes/index.php/terralivre/art icle/viewFile/115/113.> Acesso em: 06 de dezembro de 2017.

DIÉGUES JUNIOR, Manuel. O Banguê nas Alagoas: traços da influência do sistema econômico do engenho de açúcar na vida e na cultura regional. $3^{\circ}$ ed. Maceió: Edufal, 2006.

MORAES, Sérgio Roberto Cavalcanti. Pilar das Alagoas, Recanto das Coisas Boas. Maceió: Magenta Gráfica e Editora, 2005.

SÁ, Eloi Brandão. Os Velhos Caminhos de Viçosa. Maceió: SENEC/AL, 1976.

SANT’ANA, Moacir Medeiros de. Construção à história do açúcar em Alagoas. Maceió: Cepal, 2011.

SANT'ANA, Moacir Medeiros de. Pilarenses Ilustres: precedido de um estudo histórico sobre Pilar. Maceió: Cepal, 2002.

SANTOS, Milton. A natureza do espaço: técnica e tempo, razão e emoção. $4^{\circ}$ ed. São Paulo: EUSP, 2012.

SANTOS, Milton. Técnica, espaço e tempo: globalização e meio técnico-científico informacional. 3 ed. São Paulo:HUCITEC, 1997.

SILVA, Marilene Silva Costa; CRISTINA, Marta da Silva. Pilar: passado, presente e futuro. Dissertação (Graduação em Administração com Habilitação em Hotelaria), Faculdade de Alagoas - FAL, 2006.

SILVEIRA, Maris Laura da. O território em pedaços. Disponível em: $<$ http://www.comciencia.br/comciencia/handler.php?section=8\&edicao=72\&id=902. $>$ Acesso em: 08 de dezembro de 2017.

SILVEIRA, Maria Laura. Região e globalização: pensando um esquema de análise. Disponível em: $<$ http://ricardoantasjr.org/wp-content/uploads/2013/05/SILVEIRA-regiao-e-globalizaca-.pdf. $>$ Acesso em 20 de dezembro de 2017. 